\title{
The Role of CIS in the U-space Environment
}

\section{Adam Kleczatský1, Šárka Hulínská1, Jakub Kraus ${ }^{1 *}$}

\author{
${ }^{1}$ Czech Technical University in Prague, Faculty of Transportation Sciences, Department of Air Transport, Horská 3, 12803 \\ Prague, Czech Republic \\ *Corresponding author: Czech Technical University in Prague, Faculty of Transportation Sciences, Department of Air \\ Transport, Horská 3, 12803 Prague, Czech Republic, Email: kraus@fd.cvut.cz
}

\begin{abstract}
The aim of this paper is to determine the role of Common Information Service (CIS) in the U-space environment. Ensuring the correct role of the CIS and all high-level connections is the first step to implementing U-space in specific airspace and as such needs to be finished as soon as possible. The paper is based on the current state-of-the-art in the field of drones and the development of the integration of drones' operation into airspace. Options considered are based on analysing existing solutions in Europe and in the world, and the development of regulations leading to the current draft of U-space legislation. The paper presents two main possibilities of connections between U-space stakeholders and sets out eight criteria according to which both options are compared. This comparison results in considering feasibility for both options, but the one where the CIS plays a central role through which all information flows is evaluated as better.
\end{abstract}

\section{Keywords}

U-space, UAS, drone, UTM, CIS, provider, ANSP

\section{Introduction}

Unmanned aircraft have existed for almost as long as aviation itself, but only in recent years they are given special attention. This is related to the development of the manufacturing industry and information technologies, which enable fundamental miniaturization crucial for modern unmanned aircraft, together with advancement in control systems. The development of unmanned aviation also contains ideas for a system that could manage all drones' operations in the future and provide to the operators or control system all necessary information to ensure safe operation. This concept was called Unmanned Aircraft Systems Traffic Management (UTM).

"UTM was first proposed in 2016 by members of State research organizations and industry to support the real-time or near-real-time organization, coordination, and management of UA operations, including the potential for multiple beyond visual line-of-sight (BVLOS) operations. Through UTM, it is envisaged that civil aviation authorities (CAAs) and ANSPs, to the extent that they are involved, will be able to make real-time information regarding airspace constraints and flight intents available to UAS operators directly or through a UTM service provider." [1] The application of this generalized system across all member states of the European Union is called U-space [2].

This article compares possible variants of the future arrangement of the U-space system. In this comparison, it presents the advantages and disadvantages of individual options and obstacles in their application. Finally, the evaluation and selection of the best alternative is performed on the basis of defined criteria. 


\section{U-space}

U-space is created on the basis of research and development in Europe and beyond supported mainly by Single European Sky ATM Research (SESAR). The U-space cornerstone SESARsupported project is named CORUS [3]. On the other hand, many projects exist and solve more or less important part for the future of drone integration into the airspace [4].

The U-space is considered essential to respond to such growth of UAS operations - especially today in low-level airspace - which is expected to outnumber the volume of traffic currently seen with manned aircraft. Because today's air traffic management (ATM) system is already reaching its limits, it cannot be seen as the only appropriate means to safely and efficiently manage the upcoming UAS traffic. Consequently, there needs to be an alternative to it in the European regulatory framework that is adapted to the task of ensuring safe management of traffic in the U-space. [5] U-space definition is: "U-space is a set of new services and specific procedures designed to support safe, efficient and secure access to airspace for large numbers of drones." [6]

The aim of the future U-Space regulatory framework [2] is to create an effective regulatory environment that will support the ability of remote pilots, as well as operators, to access disseminated information, data and services of their choice.

\subsection{Stakeholders of U-space}

Here is the list of the most important stakeholders in the Uspace concept:

- Air Navigation Service Provider (ANSP) as an entity providing Air Navigation Services. ANSP manages air traffic and in most cases responsible for air traffic management (ATM) of specific state, or region.

- Air Traffic Service Provider (ATSP) as an entity providing Air Traffic Services, like flight information service (FIS) or aerodrome flight information service (AFIS).

- Common Information Service (CIS) provider as an entity, which shall ensure the exchange of static and dynamic information between U-space service providers and air navigation service providers, necessary for safe operations.

- U-space Service Provider (USSP) as an entity that provides U-space services to drone operators, pilots and/or drones.

- UAS operator (UASO) as a person, an organization or an enterprise engaged in or offering to engage in an aircraft operation.

\subsection{The connections in the U-space system}

The U-space system is based on a consistent exchange of information. It could not function without ensuring the exchange of information, and it is therefore necessary to correctly determine the data flows between the various stakeholders. EASA's opinion on U-space provides a suggestion of what needs to be addressed in order for U-space to comply with the legislation. However, there is some freedom in interpreting the individual requirements and it is therefore possible to provide a basic model for data exchange in several alternative solutions. Among all of the alternative solutions, two basic ones can be identified. These are shown in Figures 1 and Figure 2. Although both options formally comply with the legislation, they differ in the number of necessary connections and therefore complexity of the system. Option 1 (Figure 1) shows CIS as the real heart of the U-space system. Option 2 (Figure 2) shows literal compliance with the Regulation.

When comparing the figures, three main differences can be observed. These are:

- data source for public map,

- communication between USSPs,

- coordination between ANSPs, USSPs, ATSPs.

\section{Methodology}

In order to determine the advantages and disadvantages of individual options and thus determine the best option, it is necessary to proceed in the following steps. First determine the parameters for comparison. Then determine the method of their evaluation and finally evaluate the results.

\subsection{Parameters}

The parameters for comparing evaluated options must be determined on the basis of a system approach and all levels associated with the option must be considered, i.e. the legislative level, the technological level and the process level.

Within the legislative level, the following parameters were set:

- in-line with regulation (ILR) - the concept/high level architecture needs to be in-line with the regulation

- competitive environment (COE) - the main idea of the USSPs is to create competitive environment between the drone service providers

Within the technological level, the following parameters were set:

- Cybersecurity (CYB) - cybersecurity is a must, current ATM systems are at very high level of security and therefore centralized systems with lover numbers of stakeholders are better for this

- Integration with ATM systems (INT) - CIS and USS needs to be integrated with existing ATM systems, which requires simplicity of new systems to be easily integrable 


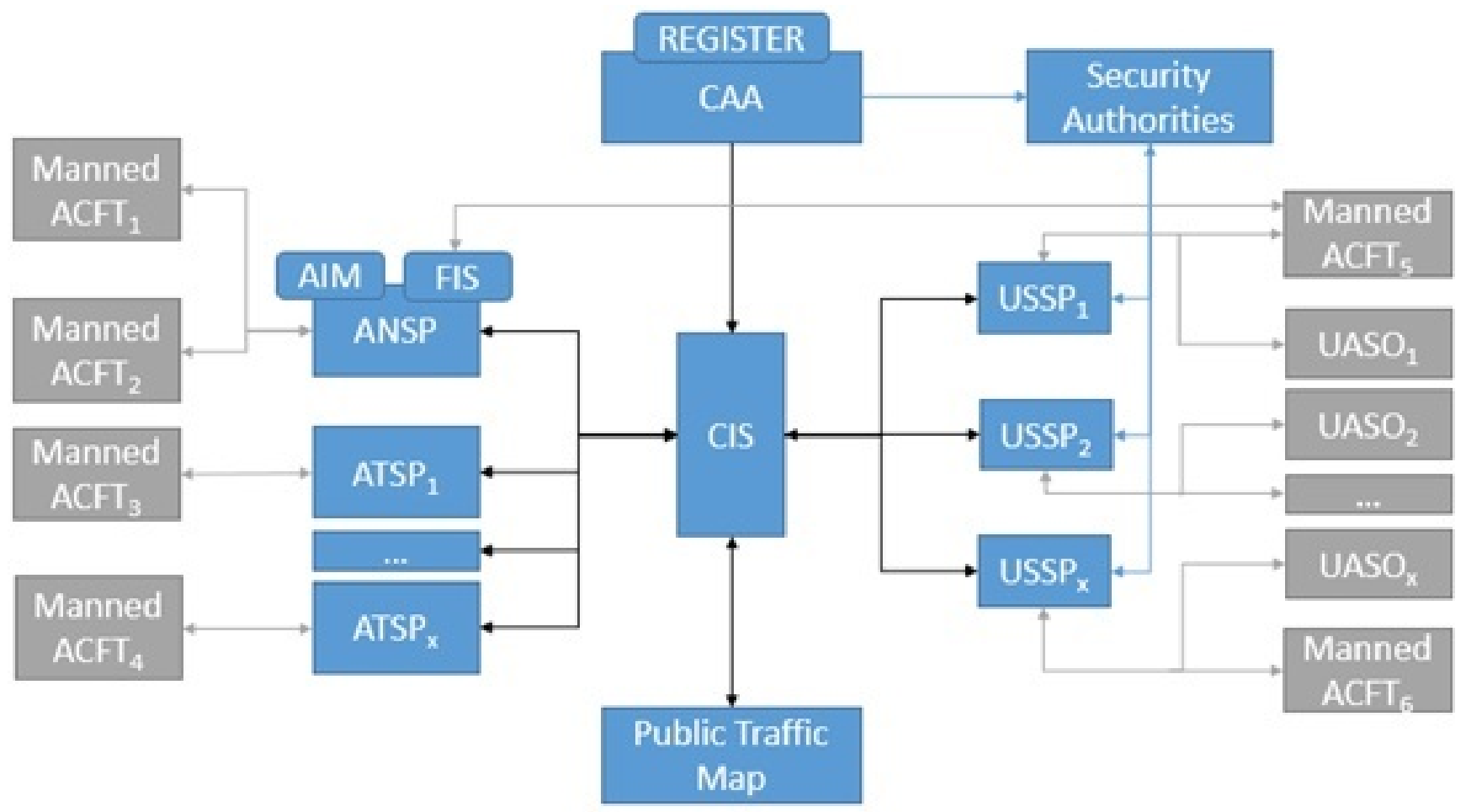

Figure 1. CIS as a real heart of the U-space

- Difficulty of supervision (DIF) - new stakeholders with new roles in aviation sector create potential for increase in supervision difficulty by Civil Aviation Authorities (CAA), which could cause mistakes and be prone to safety events realization

Within the process level, the following parameters were set:

- Ensuring safety (SAF) - aviation is regulated because of safety, the drone integration cannot decrease the acceptable level of safety

- Financial demands (FIN) - with complexness of every system solution rises also costs for its operation and maintenance

- Extent of changes (EXT) - integration of drones into the airspace should happen with as small as possible impact on manned aviation, i.e. as small as possible impact on current roles and infrastructures

\subsection{Evaluation method}

Thresholds, resp. approaches of evaluating individual parameters are directly dependent on their typology. Two groups of parameters have been identified. In the first group, it is possible to evaluate the parameter in comparison with the second option (better than / worse than). In the second group, it is possible to evaluate whether the criterion is fulfilled $=$ yes or no (fulfilled / unfulfilled). The second group thus became the exclusion group (which led to evaluation of only two options in this paper, as the other three did not meet at least one of the parameters).

\section{Results and Discussion}

The evaluation of the criteria for the first and second options can be found in Table 1 .

From the evaluation of the criteria could be seen, that both options are possible to be implemented, but Option 1 is better in more criteria and therefore the recommendations worthy.

In regard of competitive environment, the first option is worse than the second one, because putting more responsibility to CIS means less room for competitive market. In regard of cybersecurity, integration with ATM systems, financial demands and extent of changes, the first option is clearly better, as it will mean using proven concept of ATM for UTM solution.

From the safety point of view, both option should be able to ensure adequate safety, therefore not decrease the level of safety, which is the main part of today's aviation. Moreover, both option will increase the difficulty of supervision as this is completely new area, which was not in operation until these days.

Determining the right and appropriate structure for the implementation of U-space is a difficult task to solve, as this situation - the integration of drones into airspace, which is already beginning to affect existing airspace users - is a completely new thing, and therefore brings together stakeholders 


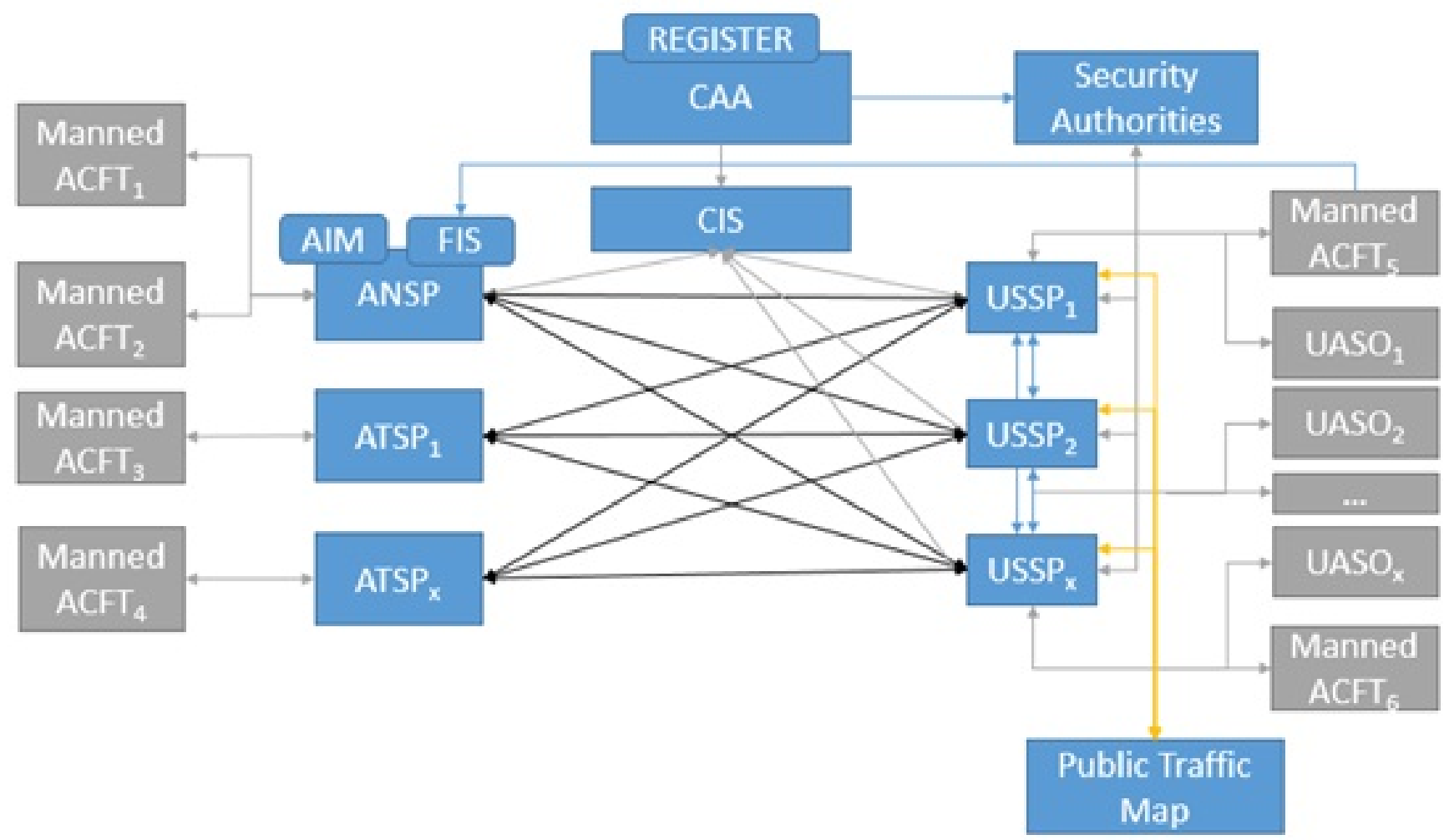

Figure 2. The connection exactly interpreted as in the opinion

Table 1. Evaluation of the criteria for option 1 and option 2

\begin{tabular}{|l|l|l|l|l|l|l|l|l|l|}
\hline \multicolumn{2}{|c|}{ Option } & ILR & COE & CYB & INT & DIF & SAF & FIN & EXT \\
\hline 1 & CIS as Heart & Yes & W & B & B & Increase & Yes & B & B \\
\hline 2 & Exactly as stated in Opinion & Yes & B & W & W & Increase & Yes & W & W \\
\hline
\end{tabular}

Yes: means that it meets the criterion; W: means worse than the second option; B: means better than the second option; Increase: means increase in supervision difficulty

who have not yet needed to cooperate together in the airspace operations management. To make the matter worse, this forthcoming change is not always perceived at national levels as positive for the development of aviation.

The proposed options submitted by the European institutions show the ambiguity of the planned legislation in such basic points as communication between stakeholders, which will form the basis of the future U-space system. The evaluation of the EASA Opinion on U-space is thus problematic and there is still the possibility that the future of the implementation of U-space in Europe will change with the possibility of affecting the planned legislation. However, gaining more time of few months can help to make corrections that will explain disputed points and thus make a significant contribution to future harmonization.

Both proposed options have their pros and cons. However, the idea of simple aviation management using ATM and the main ANSP in the region cannot be easily adapted in terms of performance or processes for sufficient safety and efficiency of the entire ecosystem, and therefore the introduction of a more comprehensive system is necessary. Option 1 reduces this complexity by proposing a CIS provider that provides more "stuff" and therefore the system is less decentralized. Option 2 , in turn, draws on this decentralization and can reduce the demands for regulated aviation components by not giving the CIS such a major role in the future drone environment.

\section{Conclusion}

The right role of the CIS in the U-space environment is the core question, the answer to which will affect aviation for decades to come. The system proposed by European legislation is a clear step forward, but it still lacks some parts to ensure the required harmonization. In this paper, two possibilities of interpretation of the legislation draft are described and it is shown that both are feasible, but with certain limitations in any option that will affect the airspace users. 


\section{References}

[1] International Civil Aviation Organization. Unmanned aircraft systems traffic management (utm) - a common framework with core principles for global harmonization. 2019. URL https:// Ww. icao.int/safety/UA/Documents/UTMFramework $\% 20$ Edition\%202.pdf.

[2] Opinion no 01/2020, high-level regulatory framework for the u-space, 2020. URL https: //www.easa.europa.eu/sites/default/ files/dfu/Opinion\%20No\%2001-2020.pdf.

[3] EUROCONTROL. Concept of operations for european utm systems (corus), 2020. URL https: //www. eurocontrol.int/project/conceptoperations-european-utm-systems.

[4] SESAR Joint Undertaking. U-space, 2020. URL https : //www. sesarju.eu/U-space.

[5] European Union Aviation Safety Agency. Draft opinion in accordance with art. 16 (accelerated procedure) of $\mathrm{mb}$ decision no 18-2015, high-level regulatory framework for the u-space, 2019.

[6] SESAR Joint Undertaking. U-space blueprint, 2017. URL https://www.sesarju.eu/sites/default/ files/documents/reports/U-space\% 20Blueprint $\% 20$ brochure 20 final. PDF. 